\title{
A comparison of high vs standard tidal volumes in ventilator weaning for individuals with sub-acute spinal cord injuries: a site-specific randomized clinical trial
}

JJ Fenton, ML Warner, D Lammertse, S Charlifue, L Martinez, A Dannels-McClure, S Kreider and C Pretz

Spinal Cord (2016) 54, 245; doi:10.1038/sc.2015.222

Correction to: Spinal Cord (2016) 54, 234-238; doi:10.1038/ sc.2015.145; published online 15 September 2015

Since the publication of this article, the authors have noticed an error in the methods section of the abstract. The section should read:

'Thirty-three ventilator requiring inpatients were randomized to either the higher (Group 1) or the standard (Group 2) Vt protocol.
Initially, all patients were ventilated at $10 \mathrm{ml} \mathrm{kg}^{-1} \mathrm{IBW} \mathrm{Vt}$ and $5 \mathrm{~cm} \mathrm{H}_{2} \mathrm{O}$ of PEEP for $72 \mathrm{~h}$. For Group 1, Vt was raised $100 \mathrm{ml}$ per day until reaching target Vt of $20 \mathrm{ml} \mathrm{kg}^{-1}$ IBW. Group 2 was maintained at $\mathrm{Vt}$ of $10 \mathrm{ml} \mathrm{kg}^{-1}$ IBW. Plateau pressures were kept at or below $30 \mathrm{~cm} \mathrm{H}_{2} \mathrm{O}$. Safety outcomes included incidence of adverse events.'

The PDF and online versions of the article have been amended. The authors apologise for any inconvenience caused. 